\title{
First-Time Home Buyers and Residential Investment Volatility*
}

\author{
Jonas D.M. Fisher \\ Federal Reserve Bank of Chicago \\ jfisher@frbchi.org
}

\author{
Martin Gervais \\ University of Southampton \\ gervais@soton.ac.uk
}

November 29, 2007

\begin{abstract}
Like other macroeconomic variables, residential investment has become much less volatile since the mid-1980s (recent experience notwithstanding.) This paper explores the role of structural change in this decline. Since the the early 1980s there have been many changes in the underlying structure of the economy, including those in the mortgage market which have made it easier to acquire a home. We examine how these changes affect residential investment volatility in a life-cycle model consistent with micro evidence on housing choices. We find that a decline in the rate of household formation, increased delay in marriage, and an increase in the cross-sectional variance of earnings drive the decline in volatility. Our findings provide support for the view that the "Great Moderation" in aggregate fluctuations is not just due to smaller aggregate shocks, but is driven at least in part by structural change.
\end{abstract}

JEL Classification Numbers: E22, E32, J11, R21

Keywords: Business Cycles; Housing; Residential Investment; First-Time Home-Buyers; Great Moderation

${ }^{*}$ We are grateful to Jay Zagorsky for giving us his NLSY net asset data. Thanks to Marco Bassetto, Jeff Campbell, Cristina DeNardi, Henry Siu, participants of the 2006 LAEF Housing Workshop and the 2005 NBER summer institute for their comments on earlier drafts of this paper. The second author gratefully acknowledge financial support from the Social Sciences and Humanities Research Council of Canada. We are grateful to Faisal Ahmed, Scott Brave, Nishat Hasan, Eric Vogt, and Saad Quayyam for research assistance. The views expressed herein are those of the authors and do not necessarily reflect those of the Federal Reserve Bank of Chicago or the Federal Reserve System. 


\section{Introduction}

Over the last twenty years macroeconomic volatility has declined significantly. Recent experience notwithstanding, residential investment's volatility has declined by more than most other aggregate variables. Strikingly, the variance of de-trended residential investment from 1984 is a fifth of what is was before then. What underlies this dramatic drop in volatility? We argue in this paper that lower rates of household formation, delayed marriage, and an increase in the cross-sectional variance of earnings account for most of the residential investment volatility decline.

There are two possible sources of a decline in economic volatility: structural change and changes to the variability of shocks affecting the economy. Obviously smaller aggregate shocks without a change in structure might account for the decline, and several authors have pointed to this possibility. ${ }^{1}$ Still, there have been many changes in the underlying structure of the economy. In the housing market there has been substantial regulatory change, the maturation of the secondary market for mortgages, and a proliferation of new mortgage products. All of these developments have made it easier to obtain a mortgage. Other structural changes with the potential to affect housing volatility include a decline in the rate of household formation due to the end of the baby boom, delayed marriage, and an increase in the cross-sectional variance of earnings. This paper disentangles the contribution of these structural changes to the decline in residential investment's volatility using a quantitative life-cycle model and evidence on housing choices from micro data. ${ }^{2}$

Our underlying hypothesis is that structural change has driven the dynamics of residential investment through its impact on the behavior of first-time home buyers. First-time home buyers, like all home buyers, are subject to various credit constraints when trying to buy a house. Since first-time buyers are typically young and so have relatively low income and savings, these constraints are likely to bind more often than for older, repeat buyers. How residential investment responds to a given aggregate

\footnotetext{
${ }^{1}$ See for example Stock and Watson (2002) and Ahmen et al. (2001).

${ }^{2} \mathrm{We}$ are not the first to examine the role of changes in financial markets on the business cycle. Closest to our work is probably Campbell and Hercowitz (2004) who study the impact of financial innovation on volatility in a two-agent infinite horizon framework with a durable consumption good. Dynan et al. (2006) survey some of the literature which seeks to understand the impact of financial innovation on aggregate volatility.
} 
shock depends on the severity of the credit constraints and the number of home buyers hoping to enter the housing market when the shock occurs. The structural changes we consider affect both the severity of credit constraints and the number of potential home buyers.

We analyze the behavior of home buyers in the National Longitudinal Survey of Youth (NLSY) and the Panel Study on Income Dynamics (PSID). The evidence we collect guides the formulation, calibration and evaluation of our model. We emphasize three main findings. First, the decision to purchase a home for the first time is closely associated with marriage. Second, in the years immediately preceding an individual's first home purchase, income and net wealth grow rapidly. Afterward, income is stable buy net wealth continues to grow, but at a slower rate. Third, home ownership and marriage occur later in the life-cycle for cohorts born later in the sample. The close connection between marriage and home ownership suggests that the initial house purchase is partly a response to a "family shock," rather than being driven entirely by wealth accumulation and portfolio allocation considerations. We incorporate this feature into our theoretical analysis.

We disentangle the contributions of the various structural changes to the dynamics of residential investment with a life-cycle model. The decision to buy a house is influenced by an exogenous shock which drives up the housing subsistence level for an individual. We assume that the larger houses needed to satisfy the induced increase in housing demand must be owned. Individuals may borrow to acquire a house, but they must satisfy a down-payment constraint to do so. We calibrate the model's stationary equilibrium to aggregate and microeconomic evidence. The calibrated model reproduces the patterns of income and asset accumulation around the time of the first purchase we find in the micro data.

To assess the impact of structural change on volatility, we simulate the dynamic response of the model economy to exogenous shocks under the regulatory, demographic, and idiosyncratic earnings regimes of the pre- and post-1984 periods. Our main finding is that most of the decline in volatility would have occurred in the absence of any change in mortgage markets, due to a reduction in the bunching of individuals near the threshold determining home-ownership brought on by a lower rate of household formation, delayed marriage, and an increase in the cross-sectional 
Table 1: The Decline in Aggregate Volatility After 1984

\begin{tabular}{lc}
\hline \hline Variable & Variance Ratio \\
\hline GDP & .22 \\
Residential Investment & .21 \\
Non-residential Investment & .56 \\
Consumer Durables & .18 \\
Non-durable Consumption & .44 \\
Services Consumption & .63 \\
\hline \hline
\end{tabular}

Note: Variance ratio is ratio of variances computed for the sample 1984-2006 to the sample 1948-1983. The quarterly data is first logged and then detrended with a band pass filter excluding periods less than 6 months and greater than 8 years.

variance of earnings.

The next section describes some of the empirical evidence which motivates our study. We then discuss our findings from the micro data. Section 4 describes our model and characterizes its solution. Calibration and simulation follows and then we conclude.

\section{Motivating Evidence}

This section discusses some of the evidence which motivates our study. We begin by documenting the decline in volatility of various components of aggregate expenditures. After this we discuss some time series evidence which suggests studying first-time home buyers may be fruitful for understanding changes in residential investment volatility. Finally, we provide a brief overview of structural change in the housing market.

\subsection{The Decline in Volatility}

Table 1 illustrates the decline in aggregate business cycle volatility. The entries are ratios of variances calculated using quarterly data over the samples 1984:I-2006:IV 
and 1947:I-1983:IV. The table indicates what many others have noticed, that there has been a broad-based decline in macroeconomic volatility. For example, GDP volatility after 1984 is just $22 \%$ of its volatility before 1984 . Of the other variables, the volatility of durable consumption expenditures and residential investment have fallen the most, slightly more than GDP as a whole and more than twice as much as any of the other expenditure components. ${ }^{3}$

\subsection{Why Study First-Time Home Buyers?}

Of all the participants in the housing market, why focus on first-time home buyers? That we focus on an aspect of the demand for housing is easily justified on empirical grounds. For instance, while the consumption price of durable equipment is strongly counter-cyclical, the consumption price of residential investment goods are strongly pro-cyclical. Much has been made of the former as justifying a focus on productivity disturbances in the investment goods producing sector. Similarly, the latter suggests a demand side interpretation for the change in residential investment's dynamics.

Fluctuations in residential investment are directly related to housing transitions between and within tenure status. Based on our analysis of the PSID, transitions between renting and owning and between owning one home and owning a different home account for the largest numbers of households and are the most closely associated with fluctuations in residential investment. Figure 1 displays annual estimates of these transitions from 1969 to 1997 based on calculations of ours using the PSID, which are described in more detail in the Data Appendix. The units for the two series are percentage of households.

The rate of transition from renting to owning is our gauge of the influence of first-time home buyers on aggregate housing dynamics. We do not focus on first-time buyers directly because of a measurement problem. Specifically, we need to observe an individual over a long time period to detect a first-time home buying event. Observing the move from renting to owning or owning to owning only requires two consecutive years of data and so are easier to measure. To the extent that we are able to measure

\footnotetext{
${ }^{3}$ Since the structural changes we focus on affect the demand for consumer durables because it is in part derived from the demand for housing, our analysis should be informative about the decline in durables volatility even though we do not model this explicitly.
} 
Figure 1: Housing Market Transitions

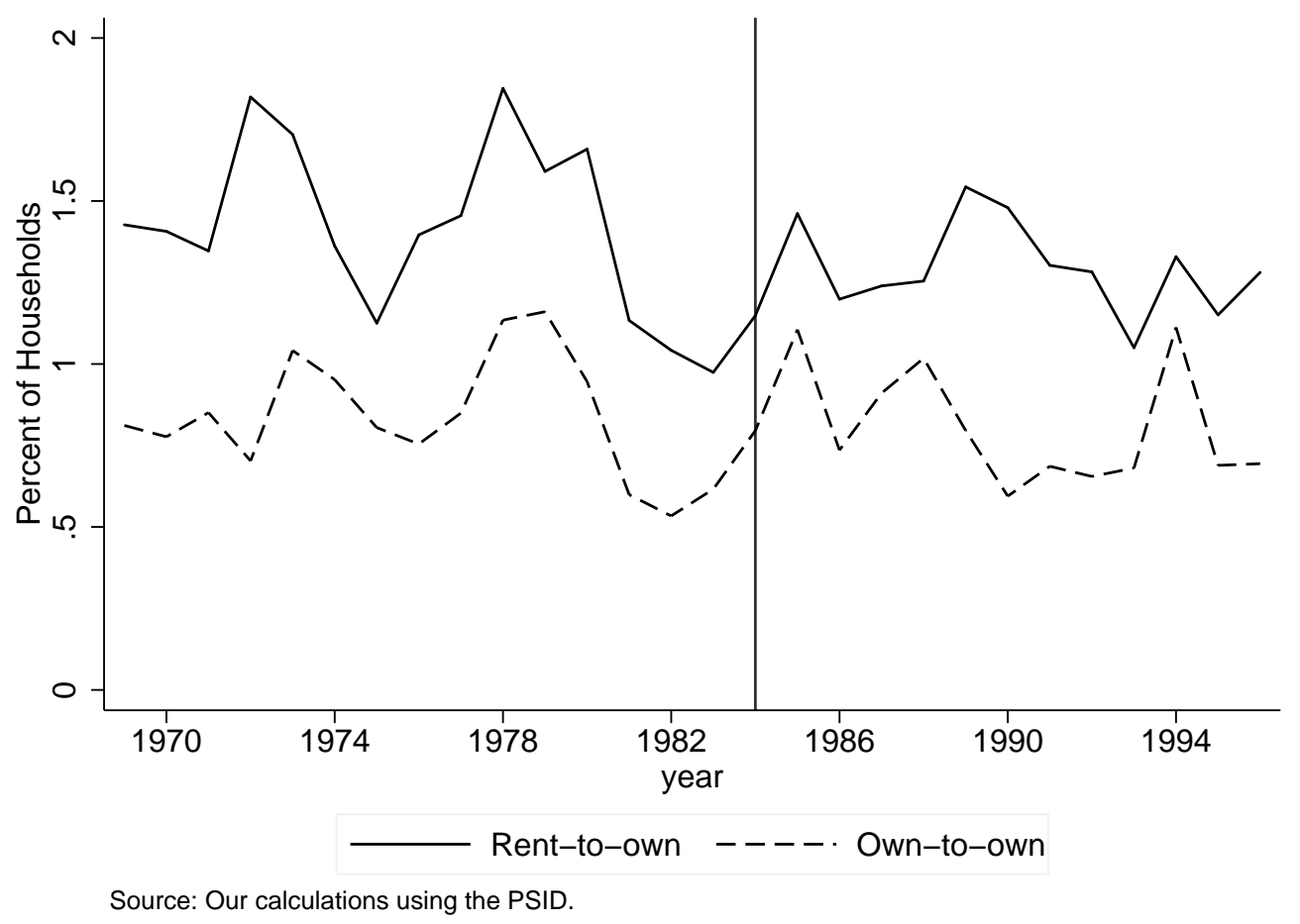

first-time buying, the majority of rent-to-own cases and its main fluctuations seem to be due to first-time buyers.

We confine our attention to those transitions involving a purposeful increase in the quantity of housing demanded. Either of the two transitions, rent-to-own or ownto-own, can result from an increase in the size of house demanded, say because of marriage, or because of a move to a higher paying job. We assume that the demand for housing rises when one of these two events occurs and in addition there is an actual increase in the amount of housing consumed. Therefore we further restrict the sample by focusing on those transitions which involve an increase in the number of rooms in a household's home. ${ }^{4}$

\footnotetext{
${ }^{4}$ In the data, we measure those transitions associated with answering a survey question on why the household moves by saying for "productive" reasons or for "consumption" reasons (where marriage is stated explicitly as an example event.) The other categories are "Involuntary" and "Ambiguous." By excluding "Involuntary" we leave out increases in housing demand due to household dissolution, an event which influences the demand for housing which is not present in our model.
} 
Two features of the time series plotted in Figure 1 suggest that first-time home buyers may be important for understanding the change in residential investment dynamics. First, the buyers making the transition from renting to owning make up the largest fraction of households making a housing transition at any point in time, and are always greater than repeat buyers who transit from owning one home to owning again. Second, the variance of rent-to-own declines about 75 percent after 1984 compared to before, while there is only a 12 percent decline in the variance of own-to-own. The hypothesis that there has been no change in variance for the rent-to-own variable after 1984 is rejected at the 6 percent level of significance. For the own-to-own variable, this hypothesis is only rejected at the 29 percent level of significance. These differences are driven primarily by the two boom and bust episodes in the earlier sample period which are much greater in amplitude for the rent-to-own variable.

\subsection{Regulation Q}

Regulation Q has long been viewed as a source of volatility in housing, especially within the Federal Reserve System. ${ }^{5}$ The regulation was a product of the Banking Acts of 1933 and 1935. Initially, it prohibited interest on demand deposits and authorized the Federal Reserve to set interest rate ceilings on time and savings deposits at most commercial banks. Until the mid-1960s the regulation had little effect on the supply of mortgage funds because the ceilings were never binding.

The regulation began to exert substantial influence on the mortgage market after 1966. In 1966 the interest rate ceilings were extended to thrift institutions making the regulation applicable to almost all mortgage originators. As interest rates rose, the ceilings were binding for extended periods, as indicated by the shaded regions in Figure 2. When the interest ceilings were binding, funds flowed out of deposits to instruments with higher yields. In an era when mortgage lenders had limited alternative sources of funds, the consequence of this outflow was a fall in the aggregate supply of mortgage funds. Some mortgage lenders were also subject to State usury laws, so instead of raising interest rates they rationed mortgages, often by lowering

\footnotetext{
${ }^{5}$ See, for example, Gilbert (1995), McCarthy and Peach (2002), Jaffee et al. (1979), and Ryding (1990). This section builds on Gilbert (1986) and Ryding (1990).
} 
Figure 2: Regulation Q and Residential Investment

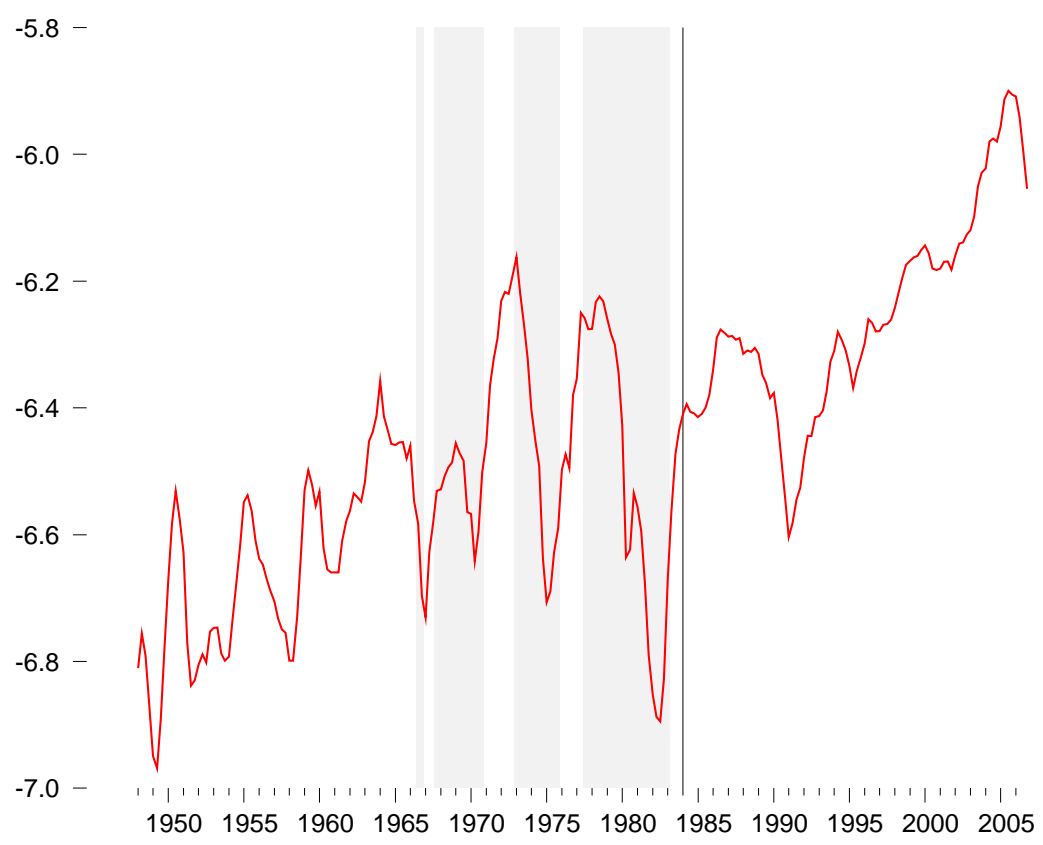

Note: Solid line - residential investment per household. Shading - periods in which interest rate ceilings were binding.

loan-to-value ratios. These considerations strongly suggest that Regulation $\mathrm{Q}$ had a destabilizing effect. Indeed, as Figure 2 shows, the periods when the interest rate ceilings were binding coincide with some of the largest fluctuations in residential investment.

As lawmakers became convinced of its destabilizing effects, Regulation Q began to be dismantled in the late 1970s. In mid-1978 depository institutions were permitted to issue large denomination "money market certificates." The Monetary Control Act of 1980 was another key development. This Act set out a timeline for phasing out interest rate ceilings and eliminated State usury restrictions on mortgages. Further deregulation followed, with banks and thrifts permitted to offer deposit products to compete with money market funds in 1982. By 1984 the interest rate ceilings were no longer binding on thrift passbook accounts and Regulation $\mathrm{Q}$ ceased to be a major factor in the mortgage market. ${ }^{6}$

${ }^{6}$ During the 1950s and early 1960s there were other forces influencing mortgage supply which had 


\subsection{Innovations in Mortgage Supply}

Since the early 1980s, as the the secondary market for mortgages has expanded dramatically and a much wider range of mortgage contracts have become available, it has become much easier to purchase a home. Moreover, through specialization improved efficiencies have lowered the cost of origination and servicing mortgages. It was understood early on that the mortgage market was undergoing fundamental change. Indeed, in his introduction to a volume describing the changes, Florida (1986) wrote "the past few years have witnessed a virtual revolution in the way this nation finances housing." Deregulation, and innovations in information technology, credit risk modelling and asset backed securitization are some of the factors which drove the changes. ${ }^{7}$

There can be little doubt that these developments have made it easier for households to obtain mortgages. One way they have done so is by reducing the cost of a given mortgage. For example, initial fees and charges for mortgages are now only a fifth of what they were at their peak in the early $1980 \mathrm{~s}^{8}{ }^{8}$ In addition, as described by Van-Order (2000), the secondary mortgage market has increased the supply of capital to mortgage markets. Lower transactions costs and a greater supply of capital have driven down mortgage interest rates relative to what they would be otherwise.

The kinds of mortgage products now available have also made it easier to obtain a mortgage. The typical mortgage before the 1980s involved the potential home buyer

effects similar in Regulation Q. At this time a large proportion of mortgages were guaranteed by the Federal Housing Administration. These mortgages were subject to interest rate ceilings so that non-price rationing would occur when market interest rates were higher than the ceilings. Another factor was the elimination of World War II era regulations which kept loan to value ratios low. In the aftermath of the Korean War these regulations were relaxed and a building boom ensued.

${ }^{7}$ Florida (1986) contains several essays describing mortgage market deregulation. Gerardi et al. (2007) provide a recent overview of how the mortgage market market has evolved. Edelberg (2003) discusses the expanded use of sophisticated credit scoring methods in the mid-1990s. The secondary market in Federally backed mortgages has been around since the 1930s. In 1970 the Federal government began sponsoring a secondary market in conventional, i.e. not Federally backed, mortgages, but it was not until the 1980s that large numbers of mortgages were securitized. By 1991 the secondary market securitized more than 40 percent of outstanding home mortgages. Ryding (1990) and Van-Order (2000) describe the evolution of the secondary market in more detail.

${ }^{8}$ This is based on data from the Federal Housing Finance Board. Some of the decrease in measured transaction costs may be due to the fact that in the late 1970s and early 1980s mortgage originators used initial fees and charges to raise the price of a mortgage when usuary laws restricted their ability to raise interest rates. 
satisfying a relatively rigid set of criteria on the loan-to-value ratio, the mortgage cost relative to income and other measures of creditworthiness. ${ }^{9}$ This rigidity can be traced to the limited development of the secondary market for conventional mortgages and regulatory restrictions which put limits on the geographic area mortgage originators could lend in. Since mortgage originators had few options to hedge against their risk, they were forced to restrict the amount of risk they could take on with any given mortgage. As the secondary market developed and geographical constraints on mortgage origination were eliminated, they were able to take on more risk with the knowledge that this risk could be offloaded in the secondary market. This has made it possible for mortgage originators to offer many new kinds of mortgage products, substantially reducing the remaining rigidities in the mortgage market. ${ }^{10}$ These developments and the lower interest rate environment were likely factors driving the rise of the home-ownership rate from 64 percent in 1995 to 69 percent in 2005, after being nearly flat for thirty years. ${ }^{11}$

How have all these changes affected the behavior of first-time home buyers? Table 2 describes how market outcomes of first-time home buyers have evolved over the last 30 years. The table confirms that over this time it has become easier for first-time home buyers to finance their first home purchase. Before and soon after mortgage deregulation, there is essentially no change in the median income of a first-time house buyer. In 1996, however, the median income of a first-time buyer is 7 percent lower and by 2005 it is 15 percent lower. Despite having a lower level of income, these buyers have been able to finance their house purchase with a much larger value to income ratio. In 1976 the median house price is 1.5 time median income, in 1996 the multiple is 2.5 , and by 2005 it is 2.8 . These more expensive houses are purchased with a down-payment of just 11 percent of the house value on average in 2005, compared

\footnotetext{
${ }^{9}$ Since the G.I. Bill of 1944, military veterans have been able to acquire Veterans Administration mortgages without a down-payment.

${ }^{10}$ Two concrete examples of the new mortgages available include those aimed at minimizing the down-payment, so called "combo loans," and those aimed at individuals with low creditworthiness, so called "sub-prime" mortgages. Sub-prime lending has been around for a long time, but only became widely available in the late 1990s. Recent turbulence in the sub-prime sector suggests that this market is still developing.

${ }^{11}$ Chambers et al. (2005) investigate the impact of changes in the structure of mortgages on the home-ownership rate within a life-cycle model. Fisher and Quayyum (2006) estimate that changes in the distribution of income and demographic factors account for roughly half the increase in the home-ownership rate.
} 
Table 2: Characteristics of First Time House Buyers

\begin{tabular}{lcccc}
\hline \hline Statistic & 1976 & 1986 & 1996 & 2005 \\
\hline Median Real Income & $\$ 35,972$ & $\$ 35,481$ & $\$ 33,151$ & $\$ 30,281$ \\
Median Price/Median Income & 1.5 & 1.9 & 2.5 & 2.8 \\
Mean Down-payment/Price & .18 & .13 & .12 & .11 \\
Mean Monthly Payment/After-Tax Income & .23 & .30 & .35 & .40 \\
\hline \hline
\end{tabular}

Notes: The table entries are from various issues of The Guarantor, 1978-1998, the 2005 National Association of Realtors Profile of Home Buyers and Sellers, and 2005 American Housing Survey. The Real median income is based on the CPI. Mean Monthly Payment/After-Tax Income before 2005 is from The The Guarantor. In 2005 we made an assumption about the average tax rate, .25, to calculate this variable.

to 13 percent in 1986 and 18 percent in 1976. To afford the higher value houses with lower income, first time buyers pay almost double the share of their after-tax income on mortgage servicing in 2005 compared to 1976. Overall, table 2 strongly suggests it has become easier for first-time home buyers to obtain a mortgage.

\subsection{The Baby Boom}

Figure 3 plots variances of log per household residential investment over the previous 40 quarters (left-hand scale) and the fraction of household heads under the age of 35 (right-hand scale). This group of household heads has the highest propensity to purchase a house for the first time. So this share variable can be viewed as a measure of the relative number of potential first-time home buyers.

Housing volatility was relatively low in the early part of the sample, rises rapidly to a peak in 1984 (corresponding to the period 1975-1984) and falls just as rapidly after 1984 to new low levels by the mid-1990s. While housing investment volatility clearly fell after 1984, there is a comparatively large housing recession in 1990-1991. The most recent recession marks a dramatic change from previous experience as residential investment hardly falls at all. As is confirmed by figure 2, the largest amplitude fluctuations in residential investment are around 1972, 1978, 1982 and 1990. These episodes coincide with periods in which the share of potential first-time 
Figure 3: The baby boom and the decline in volatility of residential investment

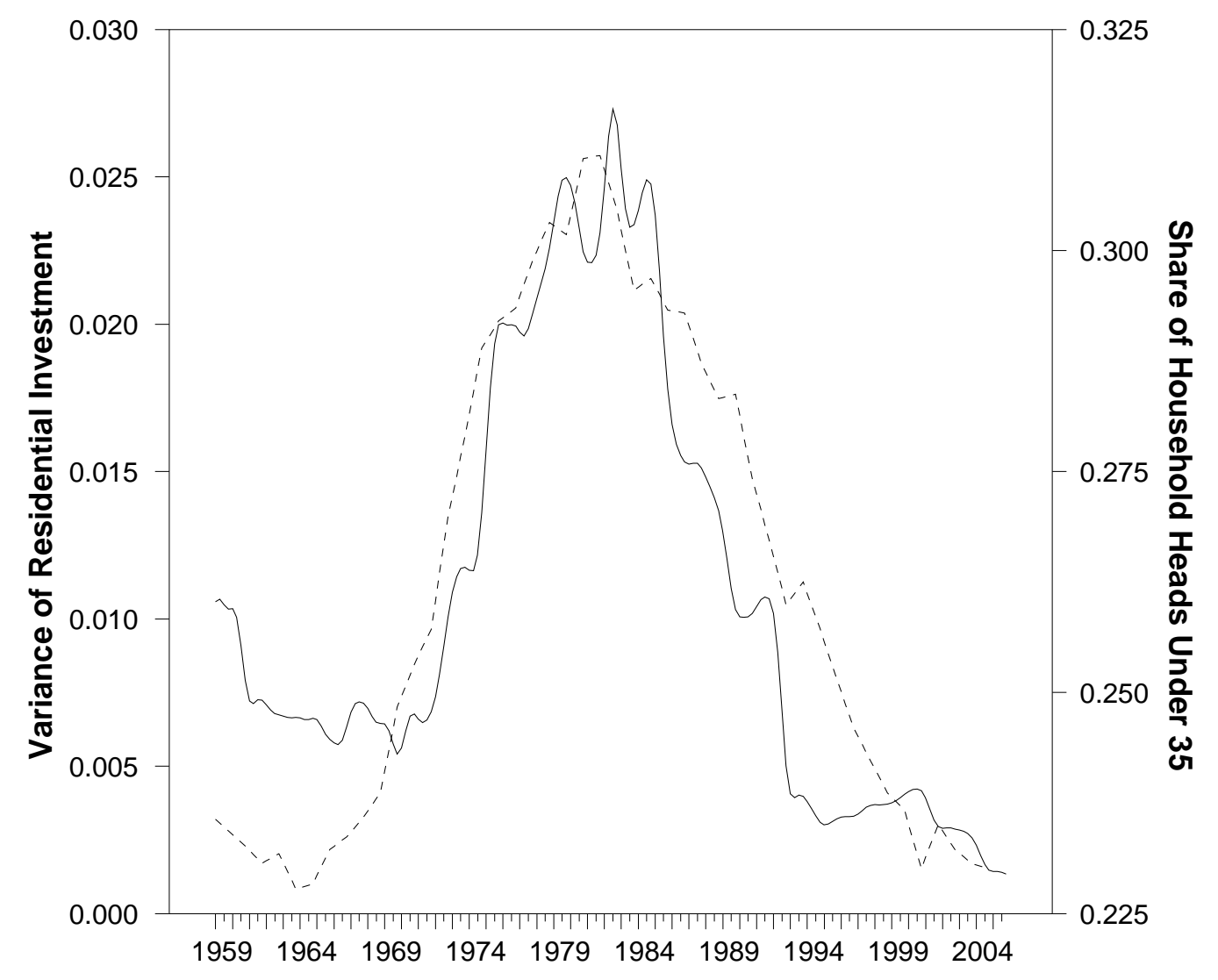

Note: Solid line - volatility of residential investment over the previous forty quarters (left-hand scale); Dashed line - share of household heads under age 35 (right-handscale).

home buyers is at its highest levels. The drastically reduced fluctuations in the 1990s and early 2000s occur as the share of potential first-time buyers reaches its lowest post-WWII levels.

An increase in the share of potential first-time home buyers increases the bunching of households near the asset and income thresholds which historically households have had to reach to obtain a mortgage. Other things equal, the degree of bunching determines the magnitude of the response of first-time home buying to a given aggregate shock. This suggest the share of potential first-time home buyers in the economy 
might have an important impact on the dynamics of residential investment. ${ }^{12}$

Two features of Figure 3 suggest that a credible explanation for the decline in volatility cannot rely on just one of the structural changes we have emphasized. First, the low share of under-35 year old household heads in the 1950s and 1960s is contemporaneous with relatively large fluctuations in residential investment. However, these fluctuations do seem less violent compared to those in the 1970s and 1980s. Second, the large drop in residential investment in the 1990 recession seems too far after the elimination of regulation $\mathrm{Q}$ and the mortgage market deregulation which unleashed growth in the secondary market and other innovations. ${ }^{13}$ However, many important financial innovations occurred after this recession. So, even if the elimination of Regulation $\mathrm{Q}$ alone seems like it would have a hard time accounting for the decline in housing volatility, mortgage innovation may still have played an important role.

\section{Evidence on the Home Ownership Decision}

The credibility of our quantitative analysis depends on us accurately representing both the decision to own a home and any structural changes as they affect the market for housing. As there have been structural changes in regulation, there have also been secular changes in social norms regarding marriage and fertility. Given that these social changes are intertwined with the decision to own a home, it is important to understand what has remained the same and any secular changes in the home ownership decision. This section describes three sets of findings along these lines. First, throughout the sample the decision to purchase a home for the first time is closely associated with marriage. Second, in the years immediately preceding an individual's first home purchase, income grows smoothly and savings accumulate rapidly. Third, home ownership and marriage occur later in the life-cycle in the second half of our sample sample compared to the first half.

\footnotetext{
${ }^{12}$ See Jaffee et al. (1979) for an early investigation into the affects of the baby boom entering the housing market.

${ }^{13}$ The 1990 housing recession may have been exacerbated by a phenomenon similar in its affects to Regulation Q. Around this time house prices in New England fell dramatically. This reduced the capitalization of many mortgage lenders who at the time had to meet new regulatory capital standards. Accordingly these banks were forced to curtail lending. Bernanke and Lown (1991) discuss the influence of this 'capital crunch' on the 1990-1991 recession.
} 


\subsection{The Data}

We study the behavior of individuals in the years before, during and after their first or second purchase of a primary residence with the NLSY79 and PSID data sets. Both data sets contain panel data on demographics, housing and income. Additionally, the NLSY79 has panel data on wealth. ${ }^{14}$ The NLSY79 started in 1979 with a sample of xxxx 14 to 22 year old individuals. These same individuals have been interviewed each year until 2000, except in 1991 and every other year from 1995. The asset data in NLSY79 begins in 1986. The PSID started in 1968 and has annual data on individuals from the original sample and from individuals added to the sample population as they enter the family histories of the original cohort. We use this data through to 1997. To address oversampling of particular sub-populations in the surveys, our estimates are based on suitably weighted observations.

We study unbalanced panels of individuals from the two surveys. In the NLSY individuals are surveyed from an early age so we can almost always determine when a first or later housing purchase is made. With the PSID we include individuals for which the year of first purchase can be determined. We assume that anyone whose first observation is as a renter and is no more than 25 years old has never owned. In the PSID we exclude individuals who enter the sample over the age of 25 . We require an individual to be a head of household or spouse of head before they can be classified as a homeowner.

The variables we focus on are housing tenure, income, net assets, marital status and age. Individuals who are household heads or their spouses are both classified as owning their house. All other individuals, including those living with their parents or other family member, are classified as renters. An individual who gets married to someone who already owns a house is classified as moving from renting to owning in the year they get married. Income for an individual is defined as the sum of the individual's labor income and any spousal labor income. Net assets are defined, as in Zagorsky (1999), as the sum of home value, cash, stockholdings, trust holdings, business equity, car value, IRA holdings, certificates of deposit, 401(k) holdings and non-car durables goods, less the sum of mortgage and other property debt, car debt

\footnotetext{
${ }^{14}$ See Haurin et al. (1996) for an earlier investigation of net asset accumulation and the first home purchase in the NLSY.
} 
Figure 4: Home Ownership and Marriage Rates
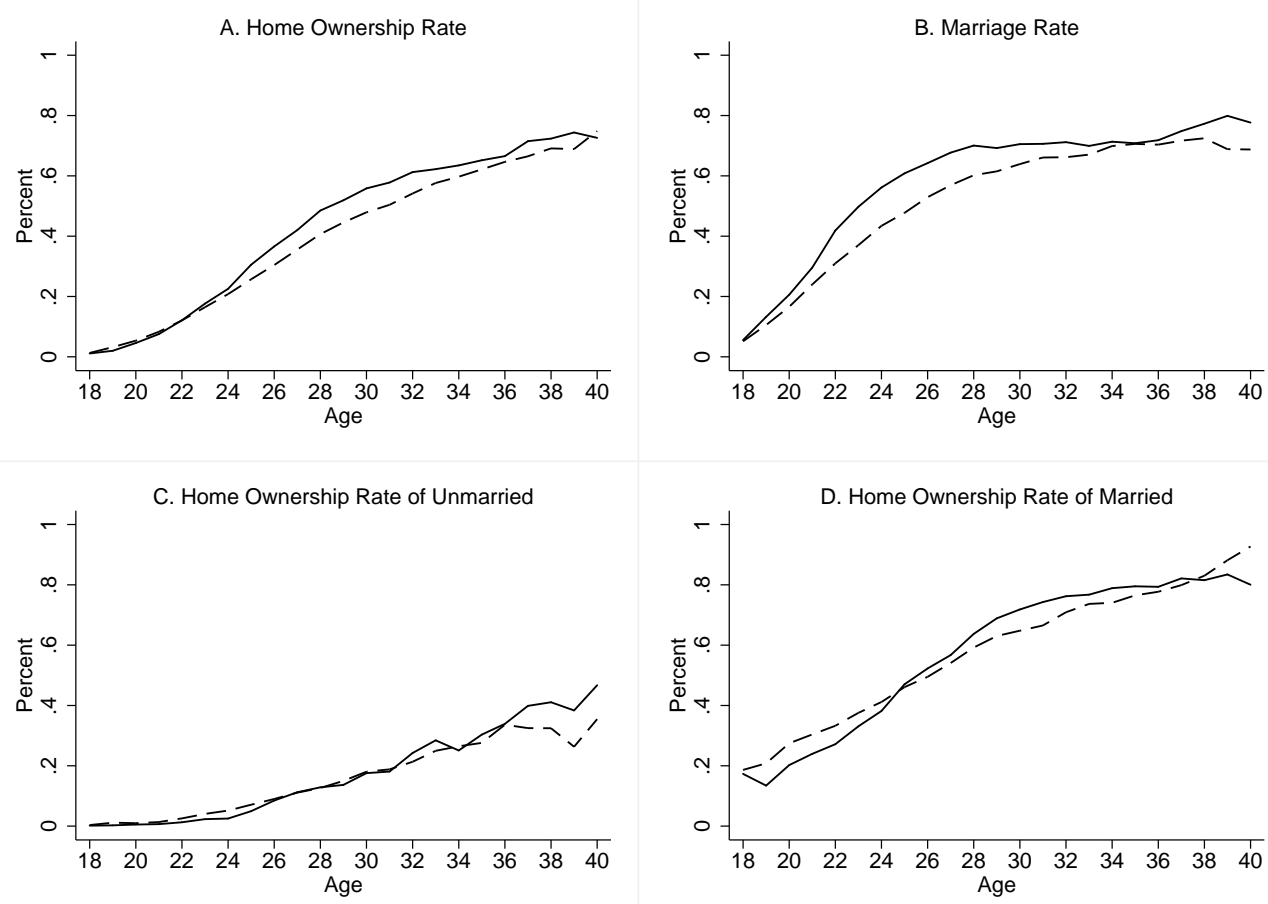

Note: These estimates are from the PSID. The ownership and marriage rates correspond to two 14-22 year old cohorts followed from 1968 (solid lines) and 1979 (dashed lines).

and any other debt. Net assets are measured as the sum of individual and spousal net assets.

\subsection{Home Ownership and Marriage}

In our theoretical model we assume that at an exogenously and randomly determined stage during an individual's life-cycle the individual's level of housing subsistence increases substantially. This motivates an increased demand for housing, which we assume can only be accommodated by buying a larger home. We interpret this "family" shock as the event of marriage. This sub-section examines evidence on marriage and home ownership in the PSID to see if this interpretation is warranted. 
Figure 4 illustrates home-ownership rates and marriage rates by age calculated from the PSID. Panel A shows the evolving home ownership rates (percent of household heads who own their home) for two cohorts of 14-22 year-old individuals followed from 1968 and 1979. The home ownership rate rises gradually as an individual ages in both cohorts. For the later cohort, after age 22 or so, the home ownership rate rise at a slower rate. In either sample, about three quarters of individuals who ever by a house have already done so by age 35 . We find that the marginal hazard of first time home buying peaks at 27-29 for both cohorts. ${ }^{15}$ Panel B of shows that secular changes in marriage rates are similar to those for home ownership. In particular, both home ownership and marriage are occurring later in the life-cycle in the 1979 cohort compared to the 1968 one.

Panels $\mathrm{C}$ and D show that marriage rates rise faster and remain higher for married individuals compared to unmarried ones. About $20 \%$ of married individuals are home owners in their early 20s. Unmarried individuals do not reach this rate of ownership until their early 30s. There has been much less secular change in the home buying behavior of unmarried individuals than in the overall marriage rate.

Figure 5 presents a formal characterization of the connection between home ownership and marriage. It plots conditional probabilities of being married in the years surrounding a first or second home purchase. We want to assess the extent to which marriage is associated with home purchase decisions. However, we know that age, social trends and possibly the business cycle also influence the decision to get married. ${ }^{16}$ We want to abstract from these effects to isolate the marginal likelihood of marriage at the time of the home purchase. This is accomplished by regressing a dummy variable for whether the respondent is married on a set of dummy variables for the years before, during and after the first or second purchase, plus year and age dummies. The figure plots the fitted values and $95 \%$ confidence intervals for the year relative to year of home purchase dummies. The omitted category for the "Years

\footnotetext{
${ }^{15}$ This is based on a regression of a dummy variable for the first purchase on dummy variables for age-bins and survey year. The coefficients on the age-bin dummies correspond to estimates of first-purchase hazard rates relative to the omitted age-bin.

${ }^{16}$ Age matters because in the early years of the life-cycle marriage rates are increasing with age. Secular trends matter because social norms regarding marriage and childbirth have been changed. The state of the economy could matter because, for example, the likelihood of being unemployed might affect the decision to marry.
} 
Figure 5: Marriage Near Home Purchases
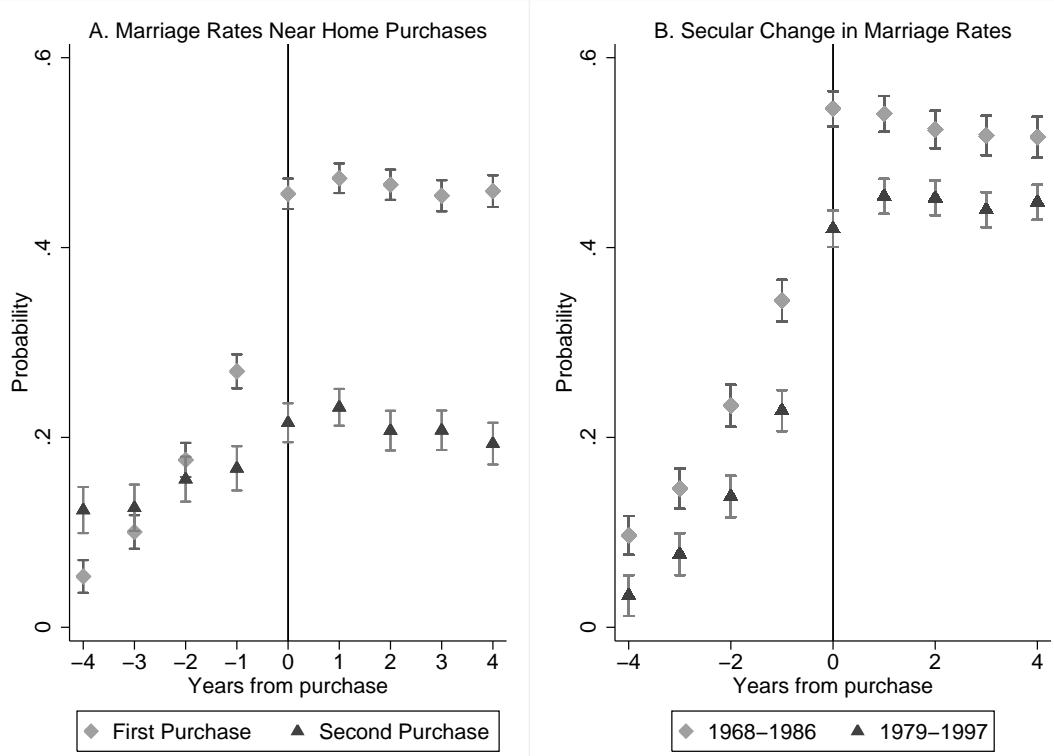

Note: These estimates are from the PSID. They correspond to coefficients from a linear probability model with categorical explanatory variables. The explanatory variables include dummy variables for each age, year and each number of years before, during and after the first or second home purchase. The coefficients corresponding to -4 to 4 years after the first or second purchase are plotted with $95 \%$ confidence intervals.

from purchase" variable in the 'First purchase' model is individuals who never own. The omitted category in the 'Second purchase' model is individuals who only ever own one home in the sample.

Figure 5's panel A reveals that marriage is more closely assoicated with the first home purchase than the second (we get similar findings looking at the third purchase as well). In the first purchase case respondents are approximately 45 percent more likely to be married compared to respondents of the same age in the same year who never buy a house. There is a big jump upward in the liklihood of being married in the year of the first purchase. After the purchase there is little change in the likelihood of being married. The qualitative pattern of marriage around the second purchase is similar but much more muted. The peak is at 20 percent in the year of the 
purchase, but there is not the jump at zero which occurs in the first case. We draw two conclusions from this plot. First, marriage and home purchases occur at similar times. Second, marriage is much more associated with the first than the second home purchase.

Figure 5's panel B illustrates the secular change in the dynamics of marriage and the first home purchase. There is a tight connection between marriage and the first home purchase in the 1968-1986 and the 1979-1997 sample periods. However, the trend toward later marriages has weakened the relationship. Note that this reduction is in addition to the secular decline in marriage rates by age which is accounted for in our regression model by the year dummies. Since individuals purchase homes for reasons other than family formation, we expect the association between marriage and the first-purchase to decline if individuals marry later.

\subsection{Income and Asset Accumulation}

Figure 6 show household net assets and wage income around the time of the first home purchase estimated from the NLSY. We use this evidence to assess our model's success in accounting for individual home buying behavior. The figure is constructed using the same non-parametric regression as the one underlying Figure 5. The omitted category for the "Years from purchase" variable is individuals who are never observed owning. Income and net assets are displayed in proportion to the value at the time of the purchase.

Figure 6 indicates that net assets and income rise together in the years -4 to -1 . Net assets double in the last year before the purchase. Income does to change in proportion but still rises substantially between -1 and 0 . The pattern of net asset accumulation is consistent with survey evidence, reported in various issues of The Guarantor, that households on average take about two years to accumulate their down payment. When marriage occurs in our sample, the income and assets from the spouse are included in the individual's assets and income. Consequently some portion of the higher assets and income in the figure is due to marriage. For example, in the year of the purchase about half the rises in assets and income can be attributed to marriage. The sharp increase in assets during the year of the home purchase reflects households' equity in the home and suggests that respondents in the NLSY typically pay a down-payment. 
Figure 6: Household Net Assets and Income Near the First Home Purchase
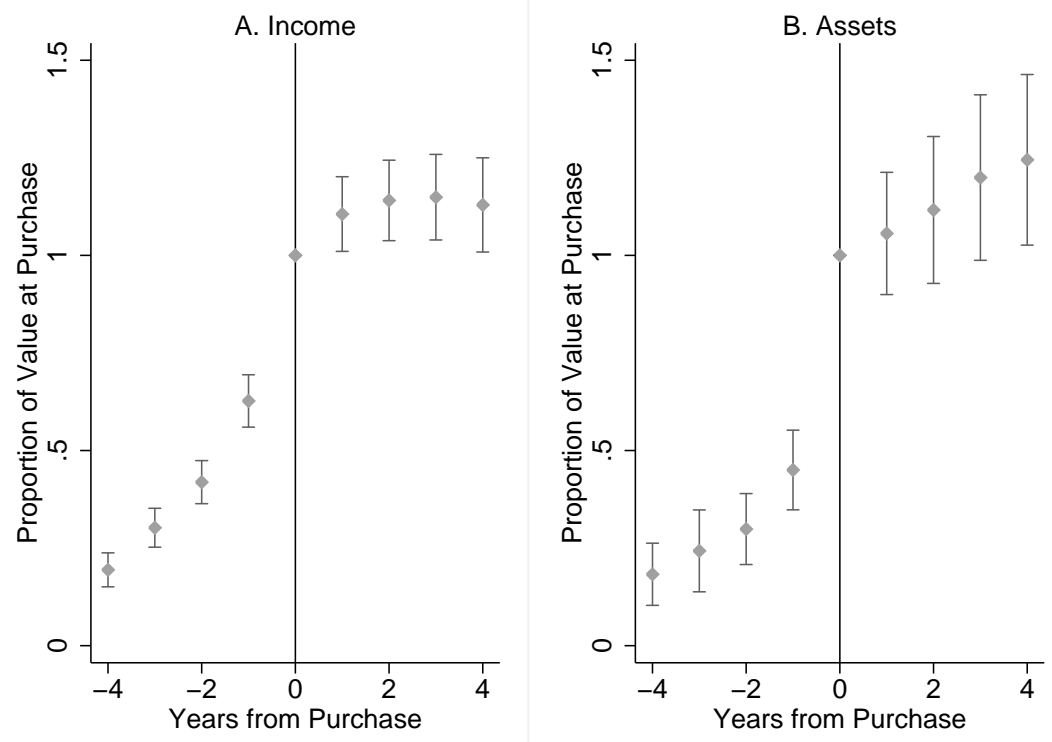

Note: These estimates are from the NLSY using the same regression model as in Figure 5 with dependent variables net assets and labor income. The coefficients for -4 to 4 years after the first purchase are plotted with $95 \%$ confidence intervals after normalizing the coefficient at zero to one.

Overall, this figure is consistent with a respondent receiving a family shock which leads her to accumulate rapidly to purchase a home. Even though the respondent may expect to eventually purchase a home in her lifetime, accumulation does not begin until she knows a home is needed soon. Income essentially level off after the year of the purchase, but nets assets continue to grow so that they are about $25 \%$ higher four years after the year of first purchase.

\section{The Model Economy}

In this section we describe our life-cycle model of housing. The evidence presented in the previous section suggests that the event of buying a house for the first time is closely related to family formation - individuals tend to become homeowners around 
the time of marriage. We model this phenomenon as exogenous changes in housing needs as individuals age through their life-cycle. When needs are high, individuals desire a larger home which cannot be rented but must be purchased. The evidence we have presented also suggests that historically households have faced financial constraints in order to become homeowners. We explicitly model two such constraints: a down-payment constraint, which limits the loan-to-value ratio at the time of purchase, and a flow constraint which limits the interest payment on a mortgage to a fraction of an individual's current labor income at the time of purchase.

\subsection{Individuals}

Preferences The economy consists of a large number of ex-ante identical individuals who forever repeat the same "life cycle" of birth, work, retirement and death. The transitions between the stages of life occur with fixed and known probabilities. Individuals care about their future selves as much as they care about their current self and so preferences are represented by

$$
U_{t}=E_{t} \sum_{j=t}^{\infty} \beta^{j-t} u\left(c_{j}, h_{j}-\bar{h}_{j}\right), \quad 0<\beta<1 .
$$

For the incarnation of the individual alive in period $j, c_{j}$ denotes the quantity of goods consumed, $h_{j}$ denotes the quantity of housing services consumed, and $\bar{h}_{j}$ denotes the subsistence level of housing. Houses come in two sizes, $h_{r}<h_{o}$. We assume that the larger size house cannot be rented. Tenure status at the beginning of the period is denoted by $x$, where $x=r$ corresponds to renting and $x=o$ corresponds to owning. For simplicity, below we drop time subscripts and use a prime symbol to denote next period's value of a variable.

Stages of the Life-cycle The state variable $s$ controls both the life-cycle status and labor earnings of individuals. Let $s \in S=\mathcal{Y} \cup \mathcal{F} \cup \mathcal{R}=\{1,2, \ldots, N\} \cup\{N+1, N+$ $2, \ldots, 2 N\} \cup\{2 N+1,2 N+2, \ldots, 3 N\}$. Individuals go through three stages of life. When $s \in \mathcal{Y}$, an individual is a young worker with low housing needs, $\bar{h}=0$ ) When $s \in \mathcal{F}$, an individual is a family worker with high housing needs, $\bar{h}=\bar{h}_{F}$. Finally, when an individual's state transits to $s \in \mathcal{R}$, the individual retires and housing needs decrease to $\bar{h}=0$. We assume $\bar{h}_{F}<h_{r}$. 
Non-retired individuals supply one unit of labor inelastically and face idiosyncratic uncertainty with respect to their labor productivity. An individual in state $s \in \mathcal{Y} \cup \mathcal{F}$ is endowed with $e(s)$ efficiency units of labor, each unit being paid after-tax wage rate $w=(1-\tau) \hat{w}$, where $\tau$ is a labor income tax and $\hat{w}$ is the before-tax wage rate. The revenues from the labor income tax are used to operate a pay-as-you-go social security system. All retired individuals are entitled to a social security payment equal to a fraction, $\theta$, of average before-tax earnings of the working population. To keep the notation consistent with working individuals, we let $e(s)=\theta \bar{e} /(1-\tau)$ if $s \in \mathcal{R}$, where $\bar{e}$ is the average labor productivity of the working-age population. Given the simple structure of this social security system, it can easily be shown that $\tau=\theta \mu_{\mathcal{R}} /\left(1-\mu_{\mathcal{R}}\right)$, where $\mu_{\mathcal{R}}$ is the fraction of the population that is retired.

The process governing an individual's state over time is described by the Markov matrix $\Pi$,

$$
\Pi=\left[\begin{array}{ccc}
\Pi_{\mathcal{Y Y}} & \Pi_{\mathcal{Y F}} & 0_{N} \\
0_{N} & \Pi_{\mathcal{F F}} & \Pi_{\mathcal{F} \mathcal{R}} \\
\Pi_{\mathcal{R Y}} & 0_{N} & \Pi_{\mathcal{R} \mathcal{R}}
\end{array}\right]
$$

where $0_{N}$ denotes an $N \times N$ matrix of zeros and the other terms are non-zero $N \times N$ matrices. Since individuals need to go through an entire life-cycle, the probability of going from set $\mathcal{Y}$ to set $\mathcal{R}$ is zero. Similarly, the probabilities of transiting from set $\mathcal{F}$ to set $\mathcal{Y}$ and set $\mathcal{R}$ to set $\mathcal{F}$ are also zero. The elements of matrix $\Pi_{\mathcal{Y Y}}$ control productivity levels while an individual is a young worker, and those of matrix $\Pi_{\mathcal{F} \mathcal{F}}$ control productivity levels of a family worker. The matrices $\Pi_{\mathcal{F} \mathcal{R}}$ and $\Pi_{\mathcal{R} \mathcal{R}}$ are diagonal. The matrix $\Pi_{\mathcal{R} Y}$ controls the probability of dying and the magnitude of intergenerational income persistence. We use $\pi_{s s^{\prime}}$ to denote individual elements of $\Pi$.

At the same time as death, a new generation of individuals of size $(1+g)$ are born. The productivity levels of the newborn are controlled by the elements of the matrix $\Pi_{\mathcal{R} \mathcal{Y}}$ as follows:

$$
\Pi_{\mathcal{R} \mathcal{Y}}=\left[\begin{array}{ccc}
\theta_{1}\left(1-\delta_{1}\right) & \cdots & \theta_{N}\left(1-\delta_{1}\right) \\
& \vdots & \\
\theta_{1}\left(1-\delta_{N}\right) & \cdots & \theta_{N}\left(1-\delta_{N}\right)
\end{array}\right],
$$

where $\delta_{n}$ is the probability of remaining retired if you retired as a type- $n$ individual, and $\left[\theta_{1}, \ldots, \theta_{N}\right]$ is the part of the invariant distribution $\Pi$ associated with the young 
stage of life. Notice that as written, the matrix $\Pi_{\mathcal{R} \mathcal{Y}}$ assumes that there is no intergenerational income persistence if the probability of dying is the same no matter which type of individual you were when you retired $\left(\delta_{j}=\delta\right.$ for all $\left.j\right)$. This is because each individual has the same probability of being any of the $N$ types of young individuals, regardless of the parent's type at the time of death.

Borrowing Constraints Individuals accumulate wealth with two types of assets: owner-occupied houses, $h_{o}$, and a generic asset called deposits, $d$, which pays interest $i_{d}$. Let $a$ denote current net worth. Renters face a non-negative savings restriction, $a^{\prime} \geq 0$. Homeowners may borrow against their house, i.e. they can acquire a mortgage. Borrowing against a home involves two constraints which affect the size of the down-payment and the amount of the mortgage payment relative to an individual's income. These constraints only apply when an individuals is changing from being a renter to a homeowner. Once the individual has a mortgage, the constraints no longer apply.

The downpayment constraint says that a mortgage acquired in the current period, $m^{\prime}$, is limited to be no more than a fraction $\gamma_{1}$ of the value of the home so that $m^{\prime} \leq\left(1-\gamma_{1}\right) h_{o}$. Current savings of an individual who chooses to be a homeowner next period are $a^{\prime}=d^{\prime}+h_{o}-m^{\prime}$. It follows that savings must be at least as big as the minimum down-payment on the house: $a^{\prime} \geq \gamma_{1} h_{o}$.

The flow constraint says that the loan payment must not exceed a fraction, $\gamma_{2}$, of labor income in the current period. Letting $i_{m}^{\prime}$ denote the interest rate on a mortgage contracted today, the flow constraint is $i_{m}^{\prime} m^{\prime} \leq \gamma_{2} w e(s)$. We assume $i_{m} \geq i_{d}$ so that individuals at least weakly prefer paying their mortgage before accumulating other assets. ${ }^{17}$ Consequently, $d^{\prime}=0$ when the flow constraint binds and we can write the flow constraint as $a^{\prime} \geq h_{o}-\gamma_{2} w e(s) / i_{m}^{\prime}$.

Comparing the two constraints reveals that there exists a threshold value of $e(s)$ such that both constraints hold with equality. For all values of $e(s)$ exceeding this threshold, the flow constraint is irrelevant, and for all values below it, the downpayment constraint is irrelevant. Therefore, we can combine the two constraints into

\footnotetext{
${ }^{17}$ When the interest rates are identical we assume individuals act as if the mortgage rate is higher.
} 
a single constraint:

$$
a^{\prime} \geq \gamma\left(s, x, x^{\prime}\right) h_{x^{\prime}}
$$

where

$$
\gamma\left(s, x, x^{\prime}\right)= \begin{cases}0, & \text { if } x^{\prime}=r \text { or } x=x^{\prime}=o . \\ \max \left\{\gamma_{1}, 1-\gamma_{2} w e(s) /\left(i_{m}^{\prime} h_{o}\right)\right\}, & \text { if } x=r \text { and } x^{\prime}=o .\end{cases}
$$

Recursive Formulation of an Individual's Problem The problem faced by an individual is to choose a sequences of consumption, asset holdings, and housing tenure choices to maximize (1), subject to (2) and the budget constraint

$$
c+p_{h} h_{x}+a^{\prime}=w e(s)+R(a, x) a+T
$$

holding in each period. Here $p_{h}$ denotes the rental price of housing and $T$ is a lump sum transfer described below. ${ }^{18}$ The function $R(a, x)$ in (3) is given by

$$
R(a, x)= \begin{cases}1+i_{d}, & \text { if } x=r \text { or if } x=o \text { and } a \geq h_{o} ; \\ 1+i_{m}-\left(i_{m}-i_{d}\right) h_{o} / a, & \text { if } x=o \text { and } a \leq h_{o} .\end{cases}
$$

This last expression takes advantage of two key facts. First, since $i_{m} \geq i_{d}$, individuals weakly prefer renting to owning a house of size $h_{r}$. Second, since individuals always at least weakly prefer paying their mortgage to accumulating non-housing assets, no individual with a fraction of equity in $[\gamma(s), 1)$ has strictly positive non-housing assets. Only renters and individuals who own their house outright accumulate non-housing assets. It follows that we can infer the size of an individual's mortgage or deposits from their savings and their tenure choice.

To describe the recursive formulation of the individual's problem, denote the value function of an individual in earnings state $s$, with net worth at the beginning of the period $a$, and tenure status $x$, by $W(s, a, x)$. The value function depends on the individual's tenure choice for tomorrow. ${ }^{19}$ Specifically,

$$
W(s, a, x) \equiv \max \left\{V_{r}(s, a, x), V_{o}(s, a, x)\right\},
$$

\footnotetext{
${ }^{18}$ The rental price of housing appears in the budget constraint for a current homeowner as an implicit payment. To keep the notation simple in writing this budget constraint we have ignored the fact that assets at the beginning of the period may have been subject to the estate tax. However this budget constraint is valid for the recursive formulation of the individual's problem.

${ }^{19}$ This value function and the ones described below also depend on the distribution of individuals over the state variables. We suppress this term for simplicity.
} 
where the first term is the value of choosing to rent tomorrow and the second term is the value of choosing to own tomorrow.

For $x^{\prime} \in\{r, o\}$, these value functions are defined as follows. The value function of an individual with state variables $(s, a, x)$ for $s \in\{Y \cup F\}$ is given by

$$
V_{x^{\prime}}(s, a, x)=\max _{a^{\prime} \geq \gamma\left(s, x, x^{\prime}\right) h_{x^{\prime}}, c} u\left(c, h_{x}-\bar{h}_{s}\right)+\beta \sum_{s^{\prime} \in S} \pi_{s s^{\prime}} W\left(s^{\prime}, a^{\prime}, x^{\prime}\right)
$$

subject to (3). The value function of an individual with state variables $(s, a, x)$ for $s \in R$ is given by

$$
\begin{aligned}
& V_{x^{\prime}}(s, a, x)= \\
& \max _{a^{\prime} \geq \gamma\left(s, x, x^{\prime}\right) h_{x^{\prime}}, c} u\left(c, h_{x}-\bar{h}_{s}\right)+\beta\left[\sum_{s^{\prime} \in R} \pi_{s s^{\prime}} W\left(s^{\prime}, a^{\prime}, x^{\prime}\right)+\sum_{s^{\prime} \in Y} \pi_{s s^{\prime}} W\left(s^{\prime},\left(1-\tau_{E}\right) a^{\prime}, r\right)\right]
\end{aligned}
$$

subject to (3). Here $\tau_{E}$ is an estate tax paid by newly born individuals. Note that if $\tau_{E}=1$, then individuals are born with zero non-housing assets. Proceeds from estate taxes are redistributed evenly among living individuals as the lump-sum transfer, $T$. Individuals are always born without a house. Upon death, houses are liquidated and put on the market for sale. Newborn young individuals are born without a house and so must rent.

\subsection{Producers}

Firms maximize profits

$$
f(k, l)-w l-p_{k} k
$$

where $f(k, l)$ is a constant returns production function, $k$ denotes non-residential capital used in production, $l$ denotes the quantity of labor employed, measured in efficiency units, and $p_{k}$ denotes the rental price of non-residential capital. We assume that producers' output can be costlessly transformed into consumption goods, and new residential and non-residential capital. Consequently, the prices of these goods are all equal to one in a competitive equilibrium. 


\subsection{Financial Intermediaries}

Capital investment and mortgage lending are undertaken by over-lapping generations of two-period-lived financial intermediaries. In the first period each intermediary issues one period securities called deposits, $d^{\prime}$, which pay interest $i_{d}^{\prime}$. The funds raised in this way are invested in capital and mortgages. Investing in residential capital involves purchasing the capital, $h^{\prime}$, at the end of the first period, renting it in the following period at price $p_{h}^{\prime}$, and selling the undepreciated portion at the end of the second period (to newly born intermediaries). Investing in non-residential capital, $k^{\prime}$, is the same except in this case the rental price is $p_{k}^{\prime}$. Investing in mortgages involves lending $m^{\prime}$ at the interest rate $i_{m}^{\prime}$. The mortgages are paid in full with interest at the end of the second period. To introduce a spread between borrowing and lending rates of interest faced by individuals, we assume there is a proportional cost to issuing mortgages. Specifically, intermediaries face the resource constraint

$$
(1+\phi) m^{\prime}+h^{\prime}+k^{\prime} \leq d^{\prime}
$$

where $\phi \geq 0$ is the cost of mortgage lending, in units of the output good. Intermediaries behave competitively and maximize profits subject to (7). The necessary conditions for optimality imply

$$
p_{h}=i_{m}+\delta_{h}, \quad p_{k}=i_{d}+\delta_{k}, \quad \text { and } \quad i_{m}=i_{d}(1+\phi),
$$

where $\delta_{h}$ and $\delta_{k}$ denote the depreciation rates of residential and non-residential capital respectively. ${ }^{20}$ Notice that the spread between the mortgage and deposit rates depends on the level of the deposit rate.

\subsection{Stationary Competitive Equilibrium}

A stationary competitive equilibrium consists of a value function $W(s, a, x)$, decision rules for savings $g(s, a, x)$ and for tenure choice $h(s, a, x)$, prices $\left\{i_{d}, i_{m}, w, p_{h}, p_{k}\right\}$, a fiscal policy $\left\{\tau, \theta, T, \tau_{E}\right\}$ and a measure $\lambda(s, a, x)$ such that

\footnotetext{
${ }^{20} \mathrm{We}$ interpret depreciation of housing as follows. Each house is subject to a probability, $\delta_{h}$, of burning down and all owners of houses participate in an actuarially fair insurance scheme. Houses are replaced instantaneously.
} 
1. The value functions and associated policy rules solve the recursive individual problem as given by equations (4)-(6);

2. Factors are paid their marginal products: $p_{k}=f_{1}(K, L), w=f_{2}(K, L)$ and (8), where $K$ and $L$ denote aggregate non-residential capital and labor input;

3. Aggregates are consistent with individual behavior, that is $\lambda(s, a, x)$ is generated by:

$$
\begin{aligned}
& \lambda\left(s^{\prime}, a^{\prime}, x^{\prime}\right)= \\
& \begin{cases}\sum_{s \in S} \pi_{s s^{\prime}} \sum_{x \in\{r, o\}} \int_{a \in A\left(s^{\prime}, a^{\prime}, x^{\prime}\right)} \lambda(s, d a, x), & \text { unless } s \in \mathcal{R}, s^{\prime} \in \mathcal{Y}, x^{\prime}=o \\
0, & \text { otherwise }\end{cases}
\end{aligned}
$$

where

$$
A\left(s^{\prime}, a^{\prime}, x^{\prime}\right)= \begin{cases}\left\{a \mid g(a, s, x) \leq a^{\prime}, h(s, a, x)=x^{\prime}\right\}, & \text { unless } s \in \mathcal{R}, s^{\prime} \in \mathcal{Y} \\ \left\{a \mid g(a, s, x) \leq\left(1-\tau_{E}\right) a^{\prime}\right\}, & \text { otherwise; }\end{cases}
$$

4. The social security (given $\theta$ ) and estate tax (given $\tau_{E}$ ) systems are individually self-financed: $\tau=\theta \mu_{\mathcal{R}} /\left(1-\mu_{\mathcal{R}}\right)$, and

$$
T=\sum_{s \in \mathcal{R}, s^{\prime} \in \mathcal{Y}} \pi_{s s^{\prime}} \sum_{x \in\{r, o\}} \int g(s, a, x) \lambda(s, d a, x)
$$

5. Markets clear:

$$
K+H=\sum_{s \in S} \sum_{x \in\{r, o\}} \int g(s, a, x) \lambda(s, d a, x)
$$

where $H$ is the aggregate stock of housing. The goods market must clear by Walras' law.

\section{Calibration}

We compare the impact of aggregate shocks on residential investment under a post1984 benchmark calibration to the impact under a calibration which represents the 
pre-1984 period. This section describes how we assign values to the model's parameters in the two calibrations. We use the post-1984 period as our benchmark because this is where the micro evidence on income and asset accumulation is from. The structural changes we consider are modelled by changing key model parameters from their values in the benchmark calibration.

\subsection{Post-1984 Benchmark Calibration}

The functional form of the utility function is given by

$$
u(c, h-\bar{h})=\ln \left[(1-\eta) c^{\rho}+\eta(h-\bar{h})^{\rho}\right] / \rho, \quad \eta \in[0,1], \rho \leq 1 .
$$

We need values for parameters governing preferences, $\left\{\beta, \eta, \rho \bar{h}_{F}\right\}$, the income process, $\left\{\Pi, e, \theta, \tau, \tau_{E}\right\}$, the production technology, $\left\{\alpha, \delta_{h}, \delta_{k}\right\}$, the size of homes, $\left\{h_{r}, h_{o}\right\}$, and mortgage constraints, $\gamma$. Our strategy is use direct evidence to assign values to the technology, income and mortgage parameters and then to choose the preference and house size parameters to bring the model as close as possible to several empirical statistics. Table 3 summarizes the parameters values we use.

The production function is $f(k, l)=k^{\alpha} l^{1-\alpha}$ and the technology parameters are $\alpha=0.3, \delta_{k}=0.092$ and $\delta_{h}=0.014$. These values correspond to means of labor's share and depreciation rates for nonresidential and residential capital calculated from NIPA data for the period 1947-2005. Our measure of nonresidential capital includes the stocks of private nonresidential capital and consumer durables. Residential capital corresponds to the stock of private residential capital.

For the income process we assume $N=3$ so that there are three income states in each life-cycle stage. Two objects need to be specified for each stage: the expected duration of the stage and the process for income conditional on being in a given stage. We assume that life begins at 18. The duration of the first stage of life is chosen so that the fraction of under-27 individuals in the economy that have not transited to the second stage equals the fraction of under-27 individuals who are unmarried for the cohort born in the period 1958-1967 reported in Table IV of Caucutt et al. (2002). We assume the second stage duration averages 37 years and the third 9 years. The conditional income process for the young and family stages are constructed using the bias-corrected version of the Tauchen and Hussey (1991) algorithm proposed by 
Floden (2007). We select autocorrelations and innovation variances for the young and family income processes using the life-cycle income process estimated from the PSID by Storesletten et al. (2004), reported in their table 2 and figure 1. The data underlying these estimates spans the two sub-samples which are the focus of this study. We assume that the life-cycle conditional variances they report are a weighted sum of variances from the early and the later sub-periods, and that the later variance is 36 percent higher than the early variance. This percentage increase is taken from Heathcote et al. (2004) who report that the cross-sectional variance of wages for the 20-59 age group is this much larger in 1990 compared to 1970. Both autocorrelations are set to .95. To complete the specification of income for the young and family stages we normalize average efficiency units of work to unity and assume average income for a family individual is 1.4 times that of a young individual. The latter value is taken from Castañeda et al. (2003). The replacement ratio for retirees is $\theta=0.4$, which is taken from Mitchell and Phillips (2006). We set the labor tax, $\tau$, to the value which finances the social security system. The estate tax is $\tau_{E}=1$ so that individuals are born without any assets.

The last four parameters we specify directly are the discount factor, the downpayment constraint, the size of owned houses related to rented houses, and the population growth rate. In keeping with related studies, we fix $\beta$ to 0.97 . The down-payment constraint, $\gamma$ is set to .12 . This is value of the mean down-payment to income ratio for 1996 in Table 2. We specify the size of owned relative to rented homes to 2.5. This is based on an analysis of the American Housing Survey described in the appendix. The population growth rate is set equal to the average growth rate of the number of households from 1980-2005, 1.3 percent.

The parameters, $\eta, \bar{h}_{F}$ and $h_{r}$, are chosen to minimize the sum of squared deviations from their empirical counterparts of the model's predictions for the ratio of nominal spending on housing to the sum of nominal consumption and housing spending, and the home-ownership rates for 20-24, 20-27, 20-30 25-64, 28-64 and 31-55 year old household heads. The first statistic is based on NIPA data for the period 1947-2005, and the remaining six statistics are averages from the 1990 and 2000 censuses.

The last parameter to select is $\rho$. We use this parameter to match the trajectory 
Table 3: Post-1984 Benchmark Calibration

\begin{tabular}{c|ll}
\hline \hline Parameter & \multicolumn{1}{|c}{ Description } & Value \\
\hline$\beta$ & Discount factor & 0.97 \\
$\eta$ & Weight on housing preferences & 0.18 \\
$h_{r}$ & Size of rental units & 1.65 \\
$h_{o}$ & Size of owner-occupied houses & 4.125 \\
$\bar{h}_{Y}$ & Minimum house size for young & 0.00 \\
$\bar{h}_{F}$ & Minimum house size for family & 1.53 \\
$\bar{h}_{R}$ & Minimum house size for retired & 0.00 \\
$\gamma$ & Minimum down-payment & 0.12 \\
$\alpha$ & Capital share of income & 0.30 \\
$\delta_{k}$ & Rate of depreciation of capital & 0.096 \\
$\delta_{h}$ & Rate of depreciation of housing capital & 0.015 \\
$\theta$ & Social security replacement ratio $)$ & 0.40 \\
\hline \hline
\end{tabular}

of net assets after a first home purchase shown in Figure 6. The parameter $\rho$ controls the degree of complementarity between housing services and consumption. If $\rho=1$ then housing and consumption are perfect substitutes. As $\rho$ is reduced, the goods become more complementary and in the limiting case $\rho \rightarrow-\infty$ the goods are perfect complements, i.e. preferences are Leontieff in consumption and housing. This latter extreme case is useful for understanding how $\rho$ affects savings. In the Leontieff case consumption is chosen to be a fixed proportion to housing, reducing the incentive to save after becoming a home-owner compared to higher values of $\rho$.

\subsection{Pre-1984 Calibration}

We consider four differences in the environment facing individuals before 1984 compared to after: a tighter down-payment constraint, faster household growth, earlier marriage and a lower cross-sectional variance of earnings. The borrowing constraint is set to $\gamma=.18$, the value of the mean down-payment to income ratio for 1976 reported in Table 2 The effect of the baby-boom on home-buying is captured by raising the population growth rate to 2.0 percent, which is the average household growth 
Table 4: Statistics for the Benchmark Economy

\begin{tabular}{lcccc}
\hline \hline & \multicolumn{2}{c}{ Pre-1984 } & \multicolumn{2}{c}{ Post-1984 } \\
& Data & Model & Data & Model \\
& & & & \\
Aggregate Quantities & 0.26 & 0.32 & 0.25 & 0.29 \\
$I / Y$ & 0.56 & 0.42 & 0.56 & 0.43 \\
$K /(K+H)$ & 0.20 & 0.23 & 0.21 & 0.21 \\
$p_{h} H /\left(C+p_{h} H\right)$ & & & & \\
Home-ownership Rates & 0.24 & 0.25 & 0.17 & 0.21 \\
$20-24$ & 0.31 & 0.33 & 0.24 & 0.28 \\
$20-27$ & 0.38 & 0.38 & 0.32 & 0.33 \\
$20-30$ & 0.68 & 0.70 & 0.65 & 0.65 \\
$25-64$ & 0.71 & 0.74 & 0.68 & 0.68 \\
$28-64$ & 0.72 & 0.76 & 0.71 & 0.69 \\
$31-55$ & & & & \\
\hline \hline
\end{tabular}

rate from 1955-1979. ${ }^{21}$ Earlier marriage is modelled by accelerating the average wait to transit from being a young to being a family individual by two years. Doing this matches the fraction of under-27 who are unmarried for the birth cohort 1948-1957 reported by Caucutt et al. (2002). We decrease the cross-sectional variance of earnings by the 36 percent value described above.

\subsection{Characteristics of the Pre- and Post-1984 Calibrations}

Table 4 displays some key features of the stationary equilibrium associated with each calibration. It shows that our model does well replicating US data in the two sample periods. In particular, the model does well reproducing the life-cycle profiles of homeownership rates in the two periods, and the fact that even though the down-payment constraint is less stringent in the Post-1984 calibration, the home-ownership rates are lower than for the Pre-1984 case. The model is less successful in its predictions for the allocation of capital across non-residential and residential uses; it predicts too

\footnotetext{
${ }^{21}$ The source is the Census Bureau. We end the sample in 1979 since the data after 1980 are calibrated to the 1980 census which introduces a break in the level of the household series in that year. In addition, there appears to be a clear break in the growth rate of households in 1980.
} 
Figure 7: Net Assets and Income in the Model and Data
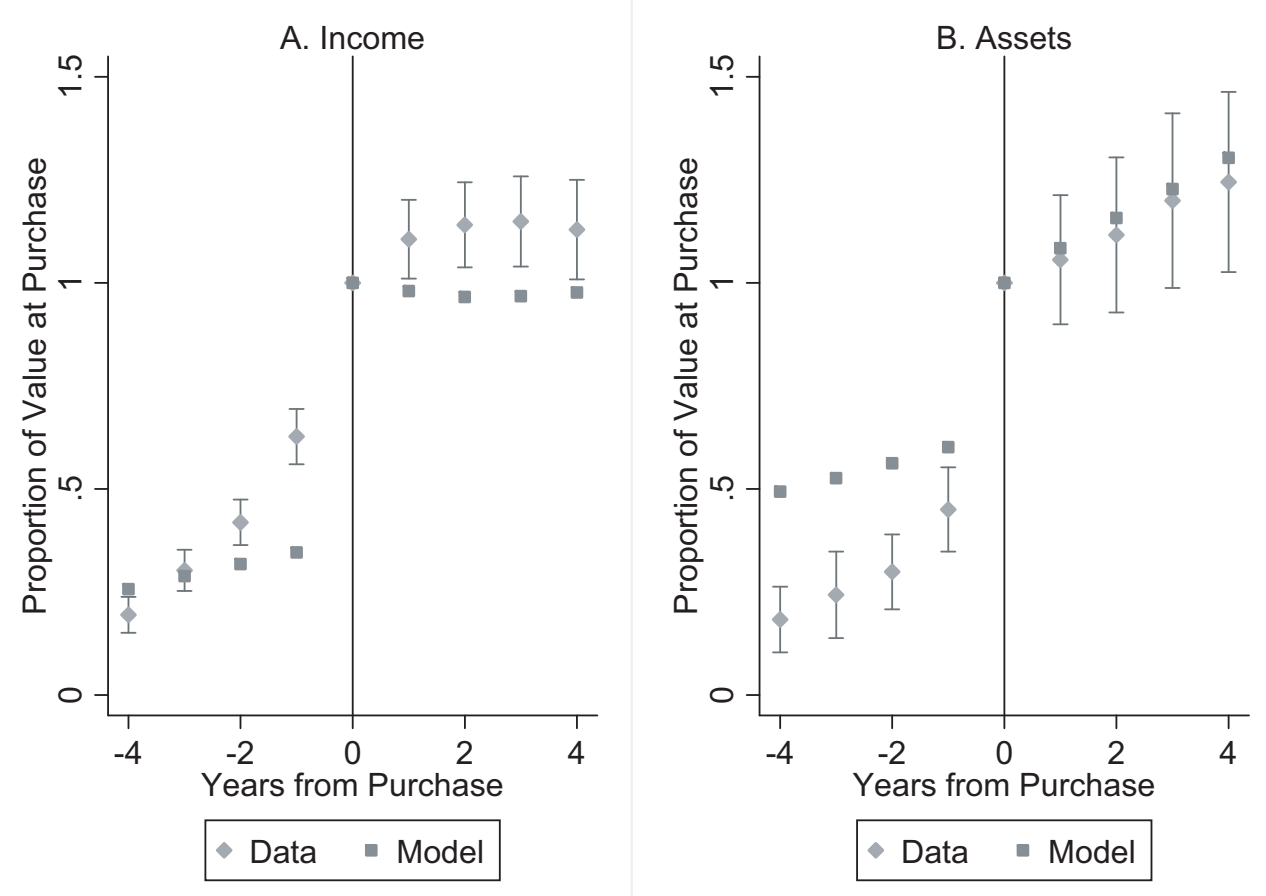

Note: Solid line - Net assets; Dashed Line - Labor income. Net assets and income have been normalized by the value at purchase.

much housing compared to the data. However, the amount of spending on housing is consistent with the data.

Figure 7 compares the profiles of income and assets around the first home purchase in our model to our estimates discussed in section 3.3. This figure shows that our model is consistent with the basic patterns in the data: both income and assets rise leading up to purchase, income flattens out afterwards, and wealth continues to grow. The main drawbacks of the model are that income and assets grow too slowly and the level of assets is too high in the four years preceding the purchase. Still, we think the qualitative success of the model justifies using it to study aggregate dynamics. 


\section{Aggregate Dynamics}

We investigate the dynamics of residential investment after two different kinds of aggregate shocks, an "interest rate" shock and an "income" shock. We calculate the investment dynamics starting from two stationary equilibria corresponding to our benchmark and pre-1984 calibrations, under the prevailing regulatory and demographic regimes.

\subsection{Methodology}

For our dynamic analysis we assume the economy is small relative to world financial markets and all goods are tradeable, but labor is not tradeable. Under our assumptions the real interest rate is exogenous, but all other prices relevant to the individual's problem are determined endogenously. We study two kinds of transitory disturbances, to the real interest rate and to labor augmenting technical change.

Consider the interest rate shock; the income shock case is similar. For simplicity we suppose there are no mortgage transactions costs, $\phi=0$, so the deposit and mortgage rates both equal the world interest rate. Suppose at date 0 the economy is in stationary equilibrium where the interest rate is $i^{*}$ and the current account is balanced. From date 0 we suppose the real interest follows a path lasting $T$ years given by $i_{1}, i_{2}, \ldots, i_{T}$, where $i_{t}$ denotes the rate of interest from year $t-1$ to $t$. After the $T$ 'th year the interest rate reverts to $i^{*}$ and the economy converges to the initial stationary equilibrium with a balanced current account.

We use backward induction to solve for the equilibrium path. We solve for the date $t$ prices $p_{k, t}, p_{h, t}$ and $w_{t}$ as well as the date $t$ stock of domestic nonresidential capital, $K_{t}$, using the following four equations

$$
\begin{aligned}
p_{k, t} & =i_{t}+\delta_{k} \\
p_{h, t} & =i_{t}+\delta_{h} \\
p_{k, t} & =F_{1}\left(K_{t}, L\right) \\
w_{t} & =F_{2}\left(K_{t}, L\right)
\end{aligned}
$$

Equation (9) is the international arbitrage condition, equation (10) is the domestic capital arbitrage condition, and equations (11) and (12) are the efficiency conditions 
from producers' capital and labor input decisions. Equations (9)-(12) also hold after date $T$ so in date $T+1$ and after all prices faced by individuals correspond to the stationary equilibrium prices. Therefore the value function of an individual for date $T+1$ is the stationary equilibrium value function, $W^{*}(s, a, x)$. Using this fact we can solve backwards for the date $T, T-1, \ldots, 0$ decisions of individuals and value functions of individuals using equations (4)-(6). Once we have individual decisions for dates $0,1,2, \ldots, T$ the transition equation for the distribution of individuals over the state space is used to compute the distribution of individuals over the state space for dates $0,1,2, \ldots, T, \ldots$ These distributions can in turn be used to compute aggregate demand for residential capital, $H_{t}^{D} \cdot{ }^{22}$ Our interest is in the dynamics of residential investment in response to the interest rate shock. This is given by

$$
X_{h, t}=H_{t+1}^{D}-\left(1-\delta_{h}\right) H_{t+1}^{D}
$$

This approach to studying aggregate dynamics is analogous to examining an impulse response function, which is the traditional approach to dynamic analysis in the business cycle literature. While our approach is analogous to traditional exercises it is different in two key respects and these are worth discussing. First, we do not compute the closed economy transition path. That is, the interest rate is taken to be exogenous, whereas it is typically endogenous in the business cycle literature. We have taken this approach so we are able to approximate how the economy responds to something resembling a monetary policy shock, without having to model such a shock explicitly. It is important to consider the impact of monetary policy shocks since they are widely viewed as having a significant impact on residential investment. Second, we have not solved the model taking into account the aggregate uncertainty we are implicitly assuming the agents in our model face. We do this to avoid taking a stand on what constitutes the entire set of shocks affecting the economy. The shocks we consider are meant to be a stand-in for all shocks which affect the economy. 
Figure 8: Responses to Interest Rate Shock

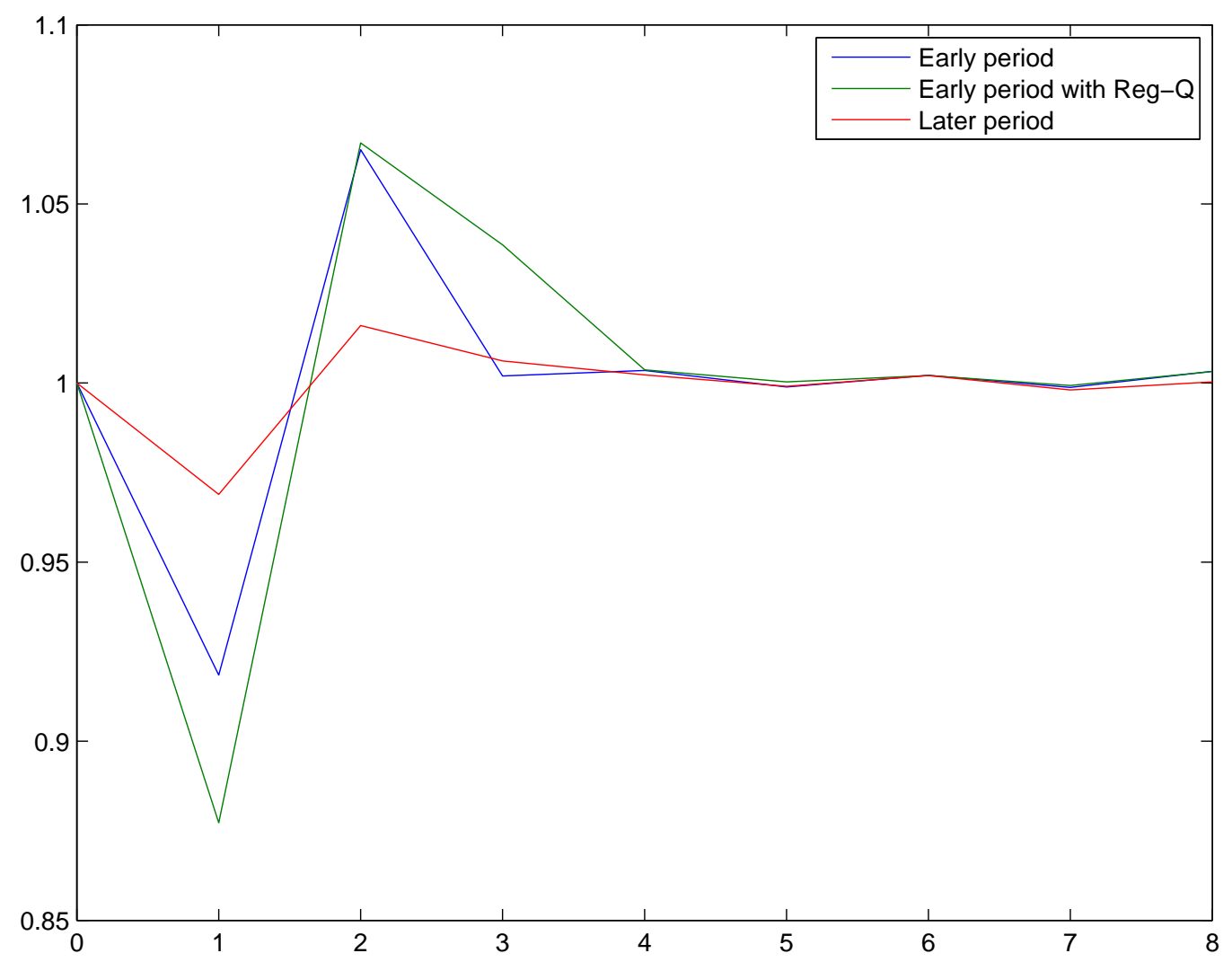

\subsection{Interest Rate Shocks}

Our interest rate shock consists of an initial increase in the interest rate followed by a gradual decline. ${ }^{23}$ This pattern is consistent with estimates of the response of interest rates to a monetary policy shock in the literature. Figure 8 displays three paths of residential investment in the face of the temporary deviation of the interest rate from its stationary equilibrium level. This shows the dynamics implied by the pre-1984 calibration with and without Regulation Q and the post-1984 calibration. Regulation $\mathrm{Q}$ is modelled as a tightening of the down-payment constraint from its

\footnotetext{
${ }^{22}$ The path of the current account is solved for using the goods market clearing condition. The corresponding path of the capital account is consistent with the dynamics of $K_{t}$ and the total demand for domestic residential capital. We do not compute the paths of the current and capital accounts since we do not need them to solve for the residential investment dynamics.

${ }^{23}$ Specifically, the interest rate deviates from its stationary equilibrium level for eight periods. The specific magnitudes of deviation are .0035, .0021, .0011, .0007, .0005, .0004, .0003, .0002
} 
Table 5: Quantifying the Effects of Structural Change

\begin{tabular}{lc}
\hline \hline & $\begin{array}{c}\text { Variance } \\
\text { Ratio }\end{array}$ \\
\hline US Data & .21 \\
Interest rate shock & \\
Total (including Reg Q) & .06 \\
Without Reg Q & .12 \\
Only change down-payment constraint & 1.13 \\
Only change $g$ & .03 \\
Only change $\sigma_{y}$ & .23 \\
Only change marriage delay & .31 \\
Only change $g, \sigma_{y}$ and marriage delay & .11 \\
& \\
Income shock & .03 \\
Total & .62 \\
Only change down-payment constraint & .03 \\
Only change $g$ & .54 \\
Only change $\sigma_{y}$ & .32 \\
Only change marriage delay & .03 \\
Only change $g, \sigma_{y}$ and marriage delay
\end{tabular}

calibrated value, .18 , for two periods: .22 in the first period of the experiment and .2 in the second period. The figure illustrates two facts. First, there is a dramatic dampening in the response of residential investment in the post-1984 case compared to the two pre-1984 cases. Second, comparing the two pre-1984 cases we see that Regulation Q can only be part of the story of the decline.

We use a statistic analogous to the variance ratio reported in Table 1 to quantify the impact of structural change. Specifically, we calculate the sum of squared responses minus one for eight periods for each response path we consider and construct ratios of responses representing the later period to responses representing the early period. If the aggregate dynamics are approximately linear in the domain of the shocks then these ratios should provide an accurate representation of how volatility changes between the two periods. Table 5 displays ratios for the two shocks corresponding to 
various scenarios designed to quantify the impact of the different structural changes.

The interest rate experiments are described in the middle panel of Table 5. For these shocks the table indicates that the overall impact of all the structural changes is to reduce volatility to just 6 percent of what it was in the Pre-1984 case. This seems very large, and is even larger than the decline in the data. Even without Regulation $\mathrm{Q}$ in the Pre-1984 period, the decline is to 12 percent. Comparing these cases we see that the elimination of Regulation Q would drop volatility by just 50 percent. So most of the effects must be due to the other structural changes. The remaining interest rate experiments are designed to disentangle the impact of these other structural changes. In each of these cases we recompute the stationary equilibrium of the Pre-1984 period with only the structural changes indicated in the table, and use this as the Post-1984 case when forming the variance ratio. ${ }^{24}$ What these experiments show is that the drop in the variance ratio including all the structural changes is entirely due to changes in population growth, increased marriage delay and the change in the cross-sectional variance of income.

What underlies this finding? First note that variation in residential investment in the model is driven entirely by changes in the numbers of individuals choosing to own, since the magnitude of the difference in house sizes is fixed. Now, consider the household's decision to own a home. This is determined by a threshold rule. For given income and tenure status, there is a threshold level of wealth which determines whether the household will own in the next period. Wealth below the threshold means the household will rent, otherwise it will own. After a shock, the thresholds change and the impact on residential investment depends on how many individuals change their tenure choice compared to the previous period. This in turn depends on the distribution of wealth near the threshold. It turns out that almost all the individuals who change there tenure decision are in the low and middle income state of the family stage of life, and of these, almost all the difference between the Pre- and Post-1984 scenarios comes from those individuals who before the shock would have switched from renting to owning, but after the shock choose to stay renting. So, by analyzing the distribution of wealth around the threshold for these individuals we can find the source of the effects in our model.

\footnotetext{
${ }^{24}$ This is not an orthogonal decomposition of variance so there is no reason for the effects to add up to the total.
} 
What we find is that each of the three non-housing-specific structural changes has, for different reasons, a large impact on the number of individuals affected by the shock. The drop in population growth means that there is a smaller fraction of individuals in the family stage of life in the later period. Remarkably, as the table indicates, this alone could be the source of the volatility decline. The increase in marriage delay means that when individuals reach the family stage they are wealthier. This has the effect of shifting the distribution of wealth to the right, lowering the fraction of individuals near the threshold. A similar affect occurs with the change in cross-sectional variance of income. In this case, increased savings occur because of the induced increase in the precautionary savings motive. The table suggests these effects are smaller than with the decline in population growth, but still sizeable. Finally, notice that the reduction in the down-payment constraint actually leads to an increase in volatility.

\subsection{Income Shocks}

The income shock is modelled as a proportional shift in the life-cycle profile of labor productivity. As such it is similar to a technology shock in a real business cycle model, except that the interest rate is kept at its stationary equilibrium level. The quantitative findings for the income shock experiments are in the bottom panel of Table 5. The findings here are very similar to the interest rate shock experiments. In particular, the overall impact on volatility is large and mostly due to the non-housingspecific structural changes. Of these, the reduction in population growth continues to be the most important driver of the volatility decline. The only substantive difference with the interest rate shock case is that here the reduction in the down-payment constraint does lead to a modest decline in volatility.

\section{Conclusion}

Our findings strongly suggest that even in the absence of structural change in the housing market, we should have seen a large decline in the volatility of residential investment. While our findings are based on studying just two kinds of aggregate 
disturbance, we think the findings hold more generally. This is because the principle mechanism driving the findings, changes in the distribution of wealth relative to the threshold determining housing tenure choice, should influence the response of the economy to any kind of shock in a similar way. Therefore, we think our findings provide support for the view that the "Great Moderation" in aggregate fluctuations is at least in part driven by structural change and is not just a result of the economy being subject to smaller aggregate shocks.

\section{Data Appendix}

\section{Calculating Housing Tenure Transitions in the PSID}

The variables in the dataset are obtained from the PSID 1968-1996 family and individual core sample files. An agent is selected into the sample if she lives in the household unit at the time of the interview, and if either one of two criteria hold: i) the agent is a household head or spouse ii) the agent is not a head or spouse but has age 18 or greater

The household weight variables are adjusted to match the household age distribution from the Census Current Population Survey (CPS). For each age bracket in the CPS, we divide the Census-determined number of households by the PSID family weight determined number of households to obtain the scale factor by which the PSID weights over- or under-represent an age group. To obtain Figure 1, the PSID adjusted weights from above are partitioned to avoid double-counting when a household changes residence. For example, when individuals from separate households marry to form a single household, it is desirable to avoid counting the home purchase twice. Thus, individuals are assigned a portion of the family weight, but rather than dividing this weight by the number of household members, we use the PSID individual weights to determine an individual's relative importance within the household, i.e. [(individual weight)/(sum of household unit's individual weights) $]^{*}$ (family weight) determines

the individual's contribution to the family weight. The sum of these contributions gives back the family unit's weight. 
The sample for the Rent-to-Own series consists of individuals who are observed transitioning from renting to owning to obtain more housing. Specifically, if the home purchased at time $t$ is physically larger than the one rented in time $t-1$. The house size is measured by the number-of-rooms indicator from the PSID family file. We further restrict the sample to those individuals who respond to the question "Why did you move?" with the by either responding for "Productive" or "Consumption" reasons. We chose these cases because they reflect deliberate moves to obtain more housing. The resulting probability is calculated using the weighting procedure from above restricted on the population who have non-missing own/rent observations at time t and time t-1. Similarly, the Own-to-Own series identifies individuals who are observed owning in both $t$ and $t-1$, but who have a move recorded in the time since the last wave's interview.

A first time home buyer is defined as a head or spouse who satisfies the following: i) observed entering the sample at age 25 or less ii) observed entering the sample renting iii) has non-missing rent observations until first instance of homeownership. Anyone transitioning from renting to owning or owning to owning (with a recorded move in residence) who is not buying their first home is "repeat buying." A nonhead, non-spouse family unit member is automatically assumed to be renting. An individual is classified as never owning if their tenure choice is observed in every year they are in the sample, and they are in the sample for at least fifteen years.

\section{Net Assets and Income in the NLSY}

Net assets and income include those for the survey respondent and their spouse, if the spouse lives with the respondent. Income is just labor income and net assets includes assets from all sources listed in the survey. To be a classified a first-time home buyer we must observe the tenure choice of the respondent for all periods up to the first time they are recorded as owning. To classified as never owning, the tenure choice of the respondent must be observed in all years they are in the sample up until the last year the survey is annual. We use the weights provided by the NLYS in our estimation to correct for the oversampling of the poor and members of the military.

\section{Calculating Relative Size of Houses for Owners and Renters in the American Housing Survey}

From 1985 The American Housing Survey (AHS) obtains the square feet size of each home in the survey. We use this measure to estimate the relative size of owned to rented homes in a manner as consistent as possible with out model. This measure of home size has the drawback that it does not account for ameneties. It has the advantage that it excludes land, which would not be the case if we focused on home value and rent. This is relevant since residential investment only measures spending 
Table 6: Average Home Size of Owned Versus Rented Homes

\begin{tabular}{lrrrrrr}
\hline \hline Measure & 1985 & 1989 & 1993 & 1997 & 2001 & 2005 \\
\hline & & & & & & \\
$(1)$ & 2.5 & 2.4 & 2.4 & 2.1 & 2.7 & 2.4 \\
$(2)$ & 2.4 & 2.3 & 2.4 & 2.1 & 2.6 & 2.4 \\
$(3)$ & 2.8 & 2.7 & 2.7 & 2.6 & 3.1 & 2.7 \\
\hline \hline
\end{tabular}

on residential structures.

We consider three different measures of home size. Each involves computing average size of owned versus rental units, but calculates size using different approaches. Measure (1) focuses on rental homes with only one person in household versus owned homes with more than one person in the household. In addition this measure restricts the sample to household heads under 30 for rental units and household heads in the age range 30-55 for owned units. (2) Restrict sample to households without children and unmarried for rental units versus owned units with married households. In addition space is measured as per adult for renters (except opposite sex couple households) versus no per adult correction for owners. (3) Measure (2) with the age restrictions of (1).

These alternative measures are intended to get closer to the concept we have in the model: there are two kinds of space - one you live in before the family shock and one you live in after the shock. By not splitting out the data like in (1)-(3), say by only looking at rental and owned units without any other restrictions to the sample, we mix up people who rent but have had the family shock with renters who have yet to have the shock. In the data one can rent a larger unit but not in our model. Measures (2) and (3) get at the idea that before the family shock, if you have a roommate the whole space in the housing unit is not really your own (at the very least you need your own room and you probably share the rent). Measures (2) and (3) do not account for homosexual couples. Not using per adult space with married cases is an attempt to get at the idea that other things the same two unmarried individuals need more space to be as well off as a married couple. The advantage of (1) is that there is no need to make implicit assumptions about how space for two or more people maps into "virtual" space for one. Opposite sex couples are assumed to be like married couples. At the very least they probably do not need an extra bedroom.

Table 6 summarizes our findings for selected years. The numbers refer to the measures listed above. Note that square feet is topcoded in the AHS. We leave the top coded values in for our calculations but expect that the ratios are downward biased because more owned dwellings tend to be topcoded than rented dwellings. With the exception of 1997 (where there are much fewer observations) the ratios 
are remarkably stable. This is true even though the size of the units varies a fair amount and is growing over time. Excluding 1997, these ratios range between 2.3 and 3.1. Excluding the largest and smallest ratio leaves a range between 2.4 and 2.8, suggesting 2.5 is a "conservative" choice. Note that these ratios are calculated for the same period we have asset data from the NLSY so they are directly relevant to our benchmark calibration period. Since the ratios seem to be relatively stable even as the average size of a type of unit is generally growing over time, we see no reason to choose a different house size ratio for the pre-1984 sample. 


\section{References}

Ahmen, S., A. Levin, and B. Wilson (2001). Recent U.S. macroeconomic stability: Good luck, good policies, or good practices? Unpublished manuscript.

Bernanke, B. S. and C. S. Lown (1991). The credit crunch. Brookings Papers on Economic Activity (2), 205-239.

Campbell, J. R. and Z. Hercowitz (2004). The role of households' collateralized debt in macroeconomic stabilization. Unpublished manuscript.

Castañeda, A., J. Días-Gímeńez, and J.-V. Ríos-Rull (2003). Accounting for earnings and wealth inequality. Journal of Political Economy 111(4), 818-857.

Caucutt, E., N. Guner, and J. Knowles (2002). Why do women wait? matching, wage inequality, and the incentives for fertility delay. Review of Economic Dynamics 5, $815-855$.

Chambers, M., C. Garriga, and D. E. Schlagenhauf (2005). Accounting for changes in the homeownership rate. Unpublished manuscript.

Dynan, K., D. W. Elmendorf, and D. E. Sichel (2006). Can financial innovation help to explain the reduced volatility of economic activity? Journal of Monetary Economics Forthcoming.

Edelberg, W. (2003). Risk-based pricing of interest rates in household loan markets. Unpublished manuscript.

Fisher, J. D. and S. Quayyum (2006). The great turn-of-the-century housing boom. Federal Reserve Bank of Chicago Economic Perspectives Third Quarter, 22-37.

Floden, M. (2007). A note on the accuracy of markov-chain approximations to highly persistent ar(1)-processes. Economics Letters forthcoming.

Florida, R. L. (Ed.) (1986). Housing and the New Financial Markets. Center for Urban Policy Research.

Gerardi, K., H. S. Rosen, and P. Willen (2007). Do households benefit from financial deregulation and innovation? the case of the mortgage market.

Gilbert, R. A. (1986). Requiem for regulation q: What it did and why it passed away. Federal Reserve Bank of New York Review February, 22-37.

Gilbert, R. A. (1995). Inside the black box: The credit channel of monetary transmission. Journal of Economic Perspectives 9(4), 27-48. 
Haurin, D. R., P. H. Hendershott, and S. M. Wachter (1996). Wealth accumulation and housing choices of young households: An exploratory investigation. Journal of Housing Research 7(1), 33-57.

Heathcote, J., K. Storesletten, and G. Violante (2004). The cross-sectional implications of rising wage inequality in the united states.

Jaffee, D. M., K. T. Rosen, B. M. Friedman, and L. R. Klein (1979). Mortgage credit availability and residential construction. Brookings Papers on Economic Activity $1979(2), 333-386-37$.

McCarthy, J. and R. W. Peach (2002). Monetary policy transmission to residential investment. Federal Reserve Bank of New York Economic Policy Review May, $139-158$.

Mitchell, O. S. and J. W. R. Phillips (2006). Social security replacement rates for alternative earnings benchmarks. University of Michigan Retirement Research Center WP 2006-116.

Ryding, J. (1990). Housing finance and the transmission of monetary policy. Federal Reserve Bank of New York Quarterly Review Summer, 42-55.

Stock, J. H. and M. W. Watson (2002). Has the business cycle changed and why? Unpublished manuscript.

Storesletten, K., C. I. Telmer, and A. Yaron (2004). Cyclical dynamics in idiosyncratic labor-market risk. Journal of Political Economy 112(3), 695-717.

Tauchen, G. and R. Hussey (1991). Quadrature-based methods for obtaining approximate solutions to nonlinear asset pricing models. Econometrica 59(2), 371-396.

Van-Order, R. (2000). The U.S. mortgage market: A model of dueling charters. Journal of Housing Research 11(2), 233-255.

Zagorsky, J. L. (1999). Young baby boomers' wealth. Review of Income and Wealth 45(2), 135-156. 